\title{
Giant congenital melanocytic nevus
}

\author{
Nevo melanocítico congênito gigante
}

\author{
Ana Carolina Leite Viana ${ }^{1}$
}

\author{
Bernardo Gontijo ${ }^{2}$
}

Flávia Vasques Bittencourt ${ }^{3}$

\begin{abstract}
Giant congenital melanocytic nevus is usually defined as a melanocytic lesion present at birth that will reach a diameter $\geq 20 \mathrm{~cm}$ in adulthood. Its incidence is estimated in <1:20,000 newborns. Despite its rarity, this lesion is important because it may associate with severe complications such as malignant melanoma, affect the central nervous system (neurocutaneous melanosis), and have major psychosocial impact on the patient and his family due to its unsightly appearance. Giant congenital melanocytic nevus generally presents as a brown lesion, with flat or mammilated surface, well-demarcated borders and hypertrichosis. Congenital melanocytic nevus is primarily a clinical diagnosis. However, congenital nevi are histologically distinguished from acquired nevi mainly by their larger size, the spread of the nevus cells to the deep layers of the skin and by their more varied architecture and morphology. Although giant congenital melanocytic nevus is recognized as a risk factor for the development of melanoma, the precise magnitude of this risk is still controversial. The estimated lifetime risk of developing melanoma varies from 5 to $10 \%$. On account of these uncertainties and the size of the lesions, the management of giant congenital melanocytic nevus needs individualization. Treatment may include surgical and non-surgical procedures, psychological intervention and/or clinical follow-up, with special attention to changes in color, texture or on the surface of the lesion. The only absolute indication for surgery in giant congenital melanocytic nevus is the development of a malignant neoplasm on the lesion.
\end{abstract}

Keywords: Nevi and melanomas; Nevus, pigmented; Skin neoplasms

Resumo: O nevo melanocítico congênito gigante é, geralmente, definido como lesão melanocítica presente ao nascimento e que atinge, no mínimo, $20 \mathrm{~cm}$ de diâmetro na vida adulta. Sua incidência é estimada em menos de 1:20.000 recém-nascidos. Contudo, apesar de sua raridade, possui importância tanto por estar associado a complicações graves, como o melanoma maligno e o acometimento do sistema nervoso central (melanose neurocutânea), quanto pelo grande impacto psicossocial que ocasiona no paciente e nos familiares, devido a seu aspecto comumente inestético. O nevo congênito gigante, geralmente, apresenta-se como lesão acastanhada, plana ou elevada, de bordas bem definidas e com hipertricose, e seu diagnóstico é eminentemente clínico. Do ponto de vista histológico, porém, os nevos melanocíticos congênitos são diferenciados dos nevos adquiridos, principalmente pelo seu tamanho maior, pela disseminação das células névicas para as camadas mais profundas da pele e pela sua arquitetura e morfologia mais variadas. O nevo congênito gigante é considerado fator de risco para o desenvolvimento do melanoma. Todavia, a real incidência de malignização ainda é controversa. Estima-se que o risco de melanoma ao longo da vida esteja entre 5 e $10 \%$. Diante dessas incertezas e do tamanho das lesões, a abordagem do nevo gigante representa um desafio e deve ser individualizada. O tratamento pode incluir procedimentos cirúrgicos ou não cirúrgicos, intervenções psicológicas e/ ou acompanhamento clínico, com atenção a mudanças de coloração, superfície ou textura do nevo. Considera-se que a única indicação absoluta para a intervenção cirúrgica é o surgimento de uma neoplasia maligna sobre a lesão.

Palavras-chave: Neoplasias cutâneas; Nevo pigmentado; Nevos e melanomas

Received on 28.10 .2012

Approved by the Advisory Board and accepted for publication on 20.12.2012

* *Work performed at the Dermatology Service at Minas Gerais Federal University Teaching Hospital (UFMG) - Belo Horizonte (MG), Brazil Financial Support: None.

Conflict of Interest: None.

MD, MSc - Voluntary dermatologist at the dermatology service at Minas Gerais Federal University Teaching Hospital (UFMG) - Belo Horizonte (MG), Brazil. MD, PhD - Associate Professor of dermatology at Minas Gerais Federal University Medical School (UFMG) - Belo Horizonte (MG), Brazil.

MD, PhD - Adjunct Professor of dermatology at Minas Gerais Federal University Medical School (UFMG) - Belo Horizonte (MG), Brazil. 


\section{INTRODUCTION}

Melanocytic nevi are benign proliferations of melanocytic cells (also known as nevus cells) arranged in nests in the epidermis, dermis or in other tissue. ${ }^{1,2}$

Melanocytic nevus present at birth is, by consensus, defined as congenital. Some authors, however, also include in this definition melanocytic nevi that develop until six months of age, during the first year or even until two years. ${ }^{1-5}$ Although congenital melanocytic nevus (CMN) develops during the intrauterine life, the occurrence of these late congenital nevi might be explained by the insufficient initial production of melanin and / or by the small size of the nevus early on, hindering its detection. ${ }^{6-9}$

Giant congenital melanocytic nevus (GCMN) is, generally defined as a congenital melanocytic lesion that will reach, at least, $20 \mathrm{~cm}$ in adult life. ${ }^{10-20}$

Despite its rarity, GCMN is important for its association with severe complications such as malignant melanoma and central nervous system (CNS) involvement, as well as a major psychosocial impact on the patient and his family, due to its unsightly appearance. ${ }^{6,11,21,22}$ The issue of deciding which is the best therapeutic approach in these cases also causes distress to the medical team, due to the controversies surrounding the treatment of these lesions - which stems largely from the uncertainties about the risks of complications. ${ }^{13,23}$

\section{HISTORY}

The interest in studying GCMN has increased over time mostly because of the hypothesis that there would be an increased risk of melanoma among these patients. Reports of individuals (usually children) with GCMN who later developed melanoma from late nineteenth and early twentieth century already raised the suspicion that these two conditions were linked..$^{20,24-26}$

However, factors such as the low incidence rates of GCMN always hindered the quantification of such risk and, even nowadays, it has not been well established in the literature. There are few studies dealing exclusively with GCMN and its relation to melanoma. Most studies also include medium melanocytic nevi or refer to CMN of all sizes (Chart 1). Moreover, among those who included only GCMN, only three research groups published prospective follow-up data. ${ }^{16,24,27}$ It is known that prospective studies with extended follow-up of patients would be necessary to establish more precisely the risk of malignant transformation of GCMN ${ }^{18,28}$ Although GCMN is considered a risk factor for the development of melanoma, the real incidence of malignancy is still a controversy. ${ }^{21,29,30}$

\section{EPIDEMIOLOGY}

About $1 \%$ of live births presents with a CMN. ${ }^{31,32}$ The incidence of GCMN is estimated at less than 1:20,000 newborns. The variety "garment-like" of GCMN is even scarcer: $1: 500,000 .^{32}$

The majority of published studies show a slightly higher prevalence of GCMN in female patients, with ratios ranging from $1.17: 1$ to $1.46: 1.12,18,19,33$

\section{PATHOGENESIS}

CMN originates between the $5^{\text {th }}$ and $24^{\text {th }}$ weeks of gestation. ${ }^{7}$ It is believed that a morphological error occurs in the neuroectoderm during embryogenesis, leading to unregulated growth of melanoblasts, the precursor cells of melanocytes. ${ }^{34}$ The histogenesis of melanocytic nevi, however, is still a matter of controversy. Recently, Saida proposed the hypothesis that both CMN and acquired nevus arise from an accelerated proliferation of cells of melanocytic lineage sometime during development. ${ }^{35}$ Therefore giant and medium CMN would be formed when proliferation starts, during migration of melanoblasts from the neural crest to the skin. Nevi will be larger and deeper when this process starts during the embryonic or early fetal periods. The later the onset of cell proliferation, the smaller the melanocytic lesion will be.

Small CMN and acquired nevus, in contrast, would arise after melanoblasts have reached the epidermis (which occurs around the $10^{\text {th }}$ week in utero, when cell differentiation begins). If melanocyte located in the dermal-epidermal junction begins to multiply shortly before birth, the result would be a small CMN. If the proliferation begins after birth, it would produce an acquired melanocytic nevus. Thus, the common origin between acquired nevus and small $\mathrm{CMN}$ would explain the clinical and histological similarity of these lesions reported in some studies. ${ }^{31,36,37}$

From a molecular standpoint, it is believed that the development of melanocytes is partially controlled by the proto-oncogenes c-met and c-kit. The hepatocyte growth factor (HGF / SF - hepatocyte growth factor or scatter factor) is a cytokine regulator of epithelial cells that express the tyrosine kinase receptor encoded by c-met. Overexpression of this factor is associated with disorders of differentiation, proliferation and migration of melanocytes and could be related to the occurrence of GCMN. ${ }^{6,38,39}$

There is evidence that the proto-oncogene c-kit, that encodes the protein kit (another tyrosine kinase receptor), allowing the binding of the stem cell factor (SCF-stem cell factor) also has an important role in the development of melanocytes. ${ }^{40}$ The expression of c-kit was observed even in proliferative nodules which appear 
CHART 1: Studies evaluating the occurrence of melanoma associated to giant congenital melanocytic nevus

\begin{tabular}{|c|c|c|c|c|c|}
\hline Authors & Country & $\begin{array}{l}\text { Year of } \\
\text { publication }\end{array}$ & $\begin{array}{l}\text { Size of CMN included } \\
\text { in the study }\end{array}$ & $\begin{array}{l}\text { Number of MM/ total } \\
\text { number of patients }\end{array}$ & $\begin{array}{l}\% \text { of patients } \\
\text { with MM }\end{array}$ \\
\hline Conway & United States $^{\dagger}$ & 1939 & Only GCMN & $4 / 40$ & $10.0 \%$ \\
\hline Greeley et al. & United States & 1965 & Giant and medium CMN & $6 / 56$ & $10.7 \%$ \\
\hline Reed et al. & United States & 1965 & Mostly GCMN & $17 / 55$ & $30.9 \%$ \\
\hline Lanier et al. & United States & 1976 & Giant and medium CMN & $5 / 72$ & $6.9 \%$ \\
\hline Lorentzen et al. & Denmark & 1977 & Giant and medium CMN & $3 / 151$ & $2.0 \%$ \\
\hline Arons \& Hurwitz & United States & 1983 & Giant and medium CMN & $0 / 46$ & $0 \%$ \\
\hline Quaba \& Wallace & United Kingdom & 1986 & Giant and medium CMN & $2 / 39$ & $5.1 \%$ \\
\hline Gari et al.* & United States & 1988 & Only GCMN & $1 / 47$ & $2.1 \%$ \\
\hline Ruiz-Maldonado et al. * & Mexico & 1992 & Only GCMN & $3 / 80$ & $3.8 \%$ \\
\hline Swerdlow et al. & United Kingdom & 1995 & Only GCMN & $2 / 26$ & $7.7 \%$ \\
\hline Marghoob et al.* & United States & 1996 & Only GCMN & $3 / 92$ & $3.3 \%$ \\
\hline Egan et al.* & United States & 1998 & Only GCMN & $2 / 46$ & $4.3 \%$ \\
\hline Bittencourt et al. ${ }^{*}$ & United States & 2000 & Only GCMN & $3 / 160$ & $1.9 \%$ \\
\hline Bohn et al. & Sweden & 2000 & Giant and medium CMN & $1 / 12$ & $8.3 \%$ \\
\hline Ka et al. & Several $^{\ddagger}$ & 2005 & Only GCMN & $0 / 379$ & $0 \%$ \\
\hline Hale et al.* & United States & 2005 & Only GCMN & $4 / 170$ & $2.4 \%$ \\
\hline Bett & Several $^{\ddagger}$ & 2005 & Giant and medium CMN & $16 / 991$ & $1.6 \%$ \\
\hline Zaal et al. & Holland & 2005 & Giant and medium CMN & $4 / 320$ & $1.3 \%$ \\
\hline Chan \& Giam & Singapore & 2006 & Giant and medium CMN & $0 / 39$ & $0 \%$ \\
\hline Kinsler et al.* & United Kingdom & 2009 & Only GCMN & $4 / 122$ & $3.3 \%$ \\
\hline Total & & 1939-2009 & & $73 / 2644$ & $2.8 \%$ \\
\hline
\end{tabular}

CMN: Congenital melanocytic nevus; GCMN: Giant congenital melanocytic nevus; MM: malignant melanoma.

* Prospective studies.

† Also included cases reported in the literature.

$\ddagger$ Internet patient registry.

Notes: - The studies by Gari, Marghoob, Bittencourt and Hale are follow-ups from the same prospective registry (New York University Giant Congenital Melanocytic Nevus Registry). In order to calculate the toatl number of cases and MM in this box, only the most recent data, from Hale et al. were included.

- Kinsler et al. evaluated several sizes of CMN, however it was possible to extract data regarding GCMN.

Modified and updated source: Marghoob et al. (2000)21

in $\mathrm{CMN} .{ }^{41}$ Although there are reports of familial cases of $\mathrm{CMN}$, most of these lesions occur in at random. ${ }^{7.42}$

\section{CLINICAL FEATURES}

GCMN usually presents as a brownish lesion with well-defined borders and hypertrichosis (Figure 1). In newborns it may have a lighter coloration and present few or no hair follicles, occurring as a macule or as an elevated lesion. ${ }^{17,43}$ The surface of the nevus may be papular, roughed, warty or cerebriform. ${ }^{17,44-46}$
Although GCMN can affect any region of the tegument, its most frequent location is the torso, followed by the limbs and head. $13,16,19,24,27,47-49$ Commonly, however, GCMN affects more than one body segment. ${ }^{27}$ Some peculiar locations led to the term "GCMN in garment". These nevi are described as "bathing trunk", "stole" or "coat sleeve," for example (Figure 2). ${ }^{50,51}$

The presence of smaller pigmented lesions scattered over the skin surface, known as satellite lesions, 
is common in individuals with GCMN, occurring in up to $78 \%$ of the cases (Figure 3). ${ }^{16,33,48}$

Although usually GCMN is an asymptomatic lesion, patients may complain of pruritus, whose mechanism is not fully understood. It is believed that symptoms may be explained by the local and intermittent stimuli of afferent sensory fibers, which would be caused by xerosis and hypohidrosis secondary to the functional impairment of adnexal structures such as sebaceous and eccrine glands..$^{11,52}$ The presence of nevus cells may also lead to the disruption of the normal skin architecture, leading to cutaneous fragility that would be responsible for the occurrence of erosions and superficial ulcerations. ${ }^{11,53}$

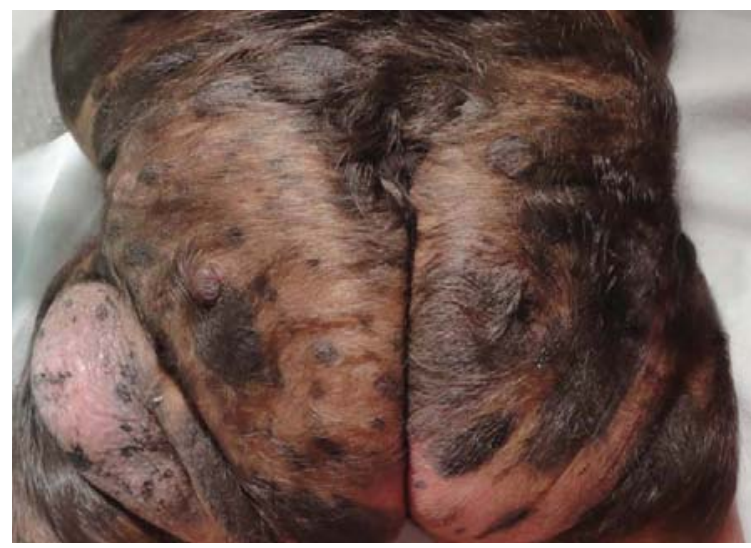

FIGURE 1: Giant congenital melanocytic nevus in "bathing trunk" with evident hypertrichosis, irregular surface and nodular areas
GCMN may also have important psychological consequences, especially when the lesions are very extensive and / or are located in visible areas such as the face. ${ }^{54} \mathrm{~A}$ study evaluating psychosocial aspects of
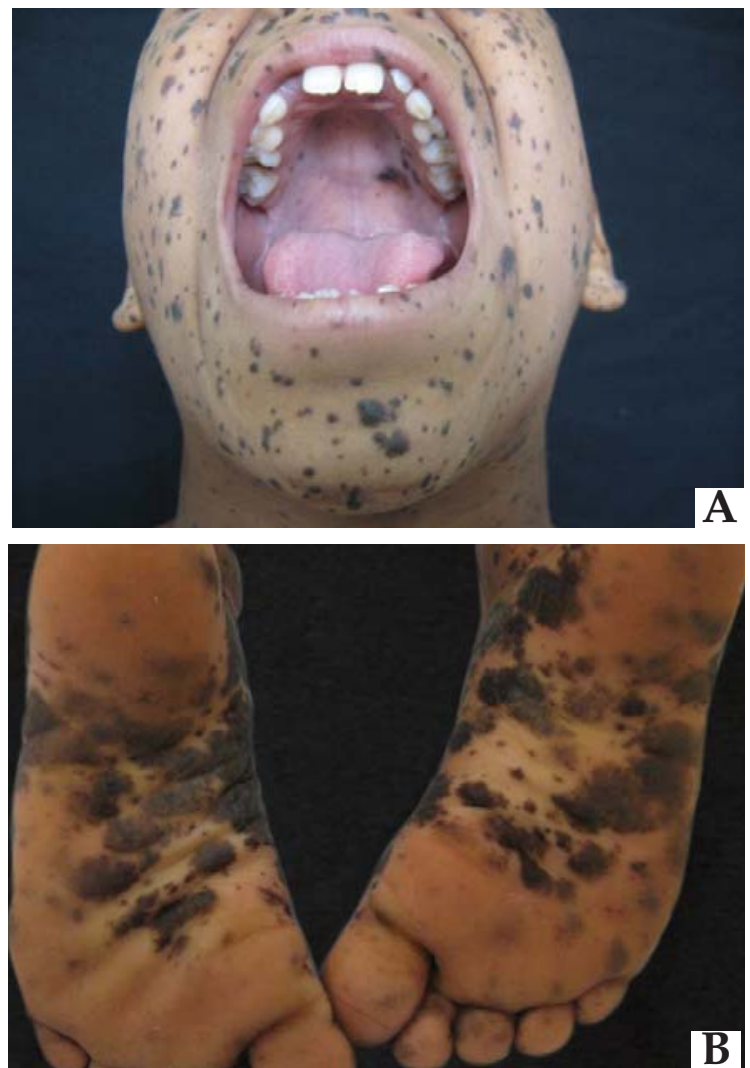

FIGURE 3: Child with multiple satellite lesions associated to giant nevus, affecting even the oral mucosa (A) and plantar areas (B)
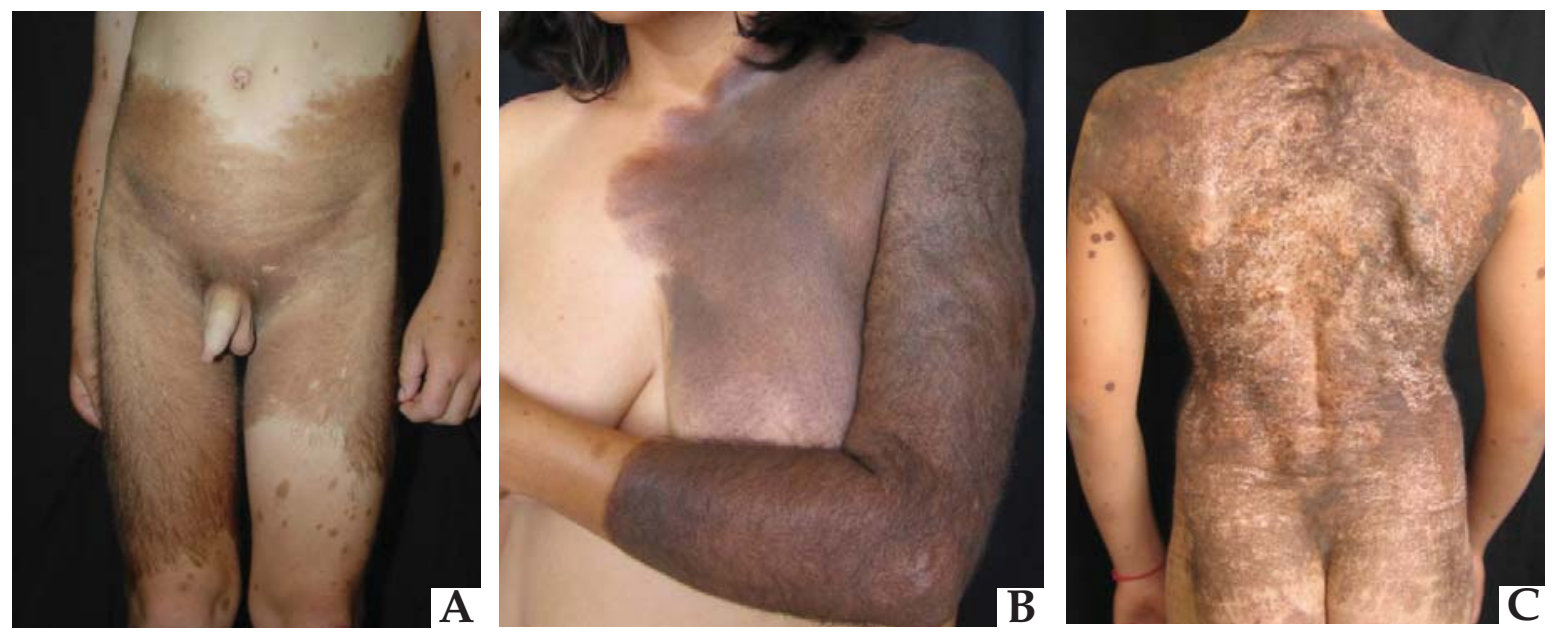

Figure 2: A. Giant congenital melanocytic nevi "in garment": A) "in bathing trunk"; (B) "in coat sleeve"; (C) type "shirt" 
children with GCMN revealed that emotional or behavioral problems occur in up to $26 \%$ of cases, and social problems affect about $30 \%$ of patients. ${ }^{22}$ These issues arise as a result of an impaired self-image caused by the presence of the nevus, the anxiety over the risk of complications such as melanoma, the discomfort caused by multiple invasive treatments and even by the unsightly appearance of surgical scars. Cutaneous symptoms eventually caused by the melanocytic lesion, contribute to the exacerbation of emotional disorders. Parents and other family members also often present with psychological symptoms associated with the difficulty in accepting the congenital problem and dealing with its implications. ${ }^{7,22,54}$

One of the serious complications of GCMN is neurocutaneous melanosis (NCM), a rare syndrome with just over 100 symptomatic cases described in the literature. It is characterized by the presence of benign or malignant melanocytic proliferations in the CNS associated with the occurrence of congenital melanocytic lesions. Melanocytic cells are found in large number (in nodules or diffusely distributed) in the leptomeninges of the brain and / or spinal cord. Although the location of these cells is similar to that occurring under physiological conditions (in up to $85 \%$ of individuals), the extent of infiltration differentiates these patients from the normal population. . $19,55-58^{-10}$

The diagnostic criteria for NCM currently accepted are those of Kadonaga \& Frieden: ${ }^{58}$

1. Presence of one GCMN or three or more CMN, associated to meningeal melanosis or meningeal melanomas.

2. No evidence of cutaneous melanoma, except in patients in whom meningeal lesions are histologically benign.

3. No evidence of meningeal melanoma, except in patients with skin lesions subjected to histological examination, and confirmed as benign.

The cases with histological confirmation of lesions in the CNS are considered final, while the others are called provisional. ${ }^{58,59}$

Several alterations on skin and other organs have been described, albeit with low frequency in association with GCMN ${ }^{6,60}$ It is believed that, in most cases, these occur in a random way. Case reports describe individuals who, in addition to GCMN, present with diffuse lipomatosis, hypertrophy of cranial bones, atrophy of limbs, skeletal asymmetries involving hyper-or hypoplasia of soft tissues, scoliosis, urinary tract anomalies, capillary vascular malformations, cafe-au-lait spots, ectopic Mongolian spots, fibroepithelial polyps and atopic dermatitis. ${ }^{4,27,54,5,5,60-63}$ The reduction on the circumference of the limb affect- ed by GCMN is common and attributed to the replacement of subcutaneous fatty tissue by nevus cells. ${ }^{27}$

Some cases of depigmentation have been reported around the nevus region (halo phenomenon), in nevus and / or in skin areas distant from it. This depigmentation is interpreted as an autoimmune phenomenon, involving a response of the immune system to melanocyte's antigens. ${ }^{27,54,60,64,65}$

Other structural CNS malformations may be found, such as arachnoid cysts, choroid plexus papilloma, cerebellar astrocytoma, spinal dysraphism (associated with GCMN located in the lumbosacral region) and type I Arnold-Chiari (herniation of cerebellar tissue through the foramen magnum). DandyWalker malformation may be associated with NCM or occur in the absence of CNS involvement by melanocytic cells. It is characterized by cystic enlargement of the fourth ventricle, aplasia or hypoplasia of the cerebellar vermis and an increase of volume of the posterior fossa with or without hydrocephaly. ${ }^{6,19,54,58,60,62,66}$

\section{CLASSIFICATION}

Attempts to classify CMN according to their size derive mainly from the fact that the risk of complications is proportional to the diameter of the nevus. ${ }^{6,9,12,16,20,67}$

Various criteria have been used by different authors to define a CMN as giant (Chart 2). ${ }^{5,18,20,25,26,26,2,32,37,5,8,68-75}$ Kopf et al. ${ }^{20}$ proposed an arbitrary classification of CMN according to their largest diameter in adulthood, dividing them into: small $(<1.5 \mathrm{~cm})$; medium (from 1.5 $\mathrm{cm}$ to $19.9 \mathrm{~cm}$ ); and large (or giant: $\geq 20 \mathrm{~cm}$ ).

The classification system proposed by Kopf et al. is the most accepted nowadays and, although the reason for the choice of values is subjective, Swerdlow et al. have shown in a retrospective study, that malignization occurred only in nevi with a diameter $\geq 20$ $\mathrm{cm} .{ }^{10-19} 25$ Moreover, the ease of obtaining the diameter of the nevus during physical examination, the accuracy of measurement in centimeters and the applicability of this classification to both adults and children make it useful for the medical practice. ${ }^{18}$

More recently, Ruiz-Maldonado ${ }^{67}$ suggested a modification to the system created by Kopf et al., defining as medium the $\mathrm{CMN}$ with an average size between 1.5 and $10 \mathrm{~cm}$; naming as large those which diameter varies between 11 and $20 \mathrm{~cm}$, and ranking as giant the nevi with more than $20 \mathrm{~cm}$. The GCMN would be further subdivided into three categories: G1 (21 to $30 \mathrm{~cm}$ ), G2 (31 to $40 \mathrm{~cm}$ ) and G3 (more than 40 $\mathrm{cm})$. Patients with giant nevi and more than 50 satellite lesions would go up a level from the category in which they were classified taking into account only the size of the nevus. The author's goals were to 
increase the classification accuracy and facilitate the comparison between different studies. This proposal, however, has not yet been incorporated in studies published to date.

In order to enable the classification of $\mathrm{CMN}$ in children, and considering that the majority of these lesions increases as the body grows, Dedavid et al. calculated the diameter of the skin surface for both sexes in different age groups, creating curves that allow us to estimate which size a CMN will reach in adulthood (Figures 4 and 5). ${ }^{9,20,37,46,76,77,78}$

Another way of obtaining an estimate of the size of $\mathrm{CMN}$ in adult life is multiplying the diameter of the lesion in the infant by a numerical factor that varies according to the location of the nevi (Table 1).,49,77,79

\section{HISTOLOGY AND OTHER COMPLEMENTARY EXAMS}

GCMN diagnosis is mainly clinical. From the histological standpoint, however, $\mathrm{CMN}$ is generally differentiated from acquired nevus mainly by its larger size, the dissemination of nevus cells into the deeper layers of the skin (including subcutaneous tissues) and its varied architecture and morphology. ${ }^{30,43,80,81}$

The epidermal alterations of CMN are often similar to those of the acquired nevus. The most common findings are hyperkeratosis and hyperplasia, elongation of epidermal ridges associated with an increased number of melanocytes and hyperpigmentation (lentigo-like alterations) and presence of melanocytes arranged in nests in the epidermis. ${ }^{30,43,82}$

CHART 2: Giant congenital melanocytic nevus classification

\begin{tabular}{|ll}
\hline Author & Criteria \\
\hline Pers (1963); Lorentzen et al. (1977) & CMN larger than the pacient's palmar area when located on head or neck and twice \\
the size of the palm when located anywhere else \\
Greeley et al. (1965) & CMN $\geq 900 \mathrm{~cm} 2$ \\
Rhodes et al. (1981); Arons \& Hurwitz (1983) & CMN that cannot be removed with primary closing in one single surgical procedure \\
Kaplan (1974) & CMN that cannot be removed without causing deformities \\
Lanier et al. (1976) & CMN affecting 30\% or more of total body surface \\
Kopf et al. (1979) & $\geq 20 \mathrm{~cm}$ in its larger diameter in adulthood \\
Solomon (1980) & $>2 \mathrm{~cm}$ \\
Castilla et al. (1981); Bauer \& Vicari (1988) & $>4 \mathrm{~cm}$ \\
Zitelli et al. (1984) & $>120 \mathrm{~cm} 2$ \\
Illig et al. (1985) & $>10 \mathrm{~cm}$ \\
Quaba \& Wallace (1986) & $>2 \%$ of total body surface \\
Kadonaga \& Frieden (1991) & $>9 \mathrm{~cm}$, when located on the head and $>6 \mathrm{~cm}$ when located on the body, in children \\
Swerdlow et al. (1995) & $>5 \%$ of total body surface
\end{tabular}

CMN: congenital melanocytic nevi

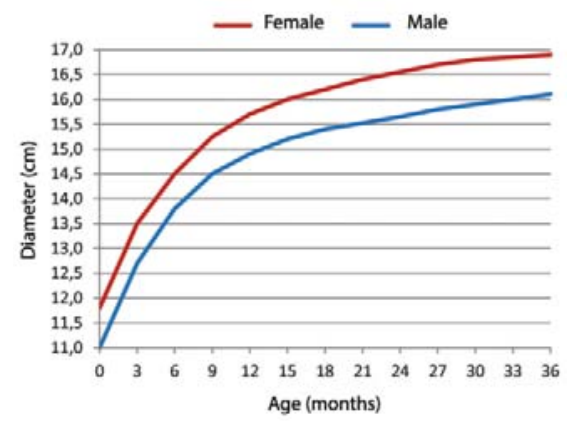

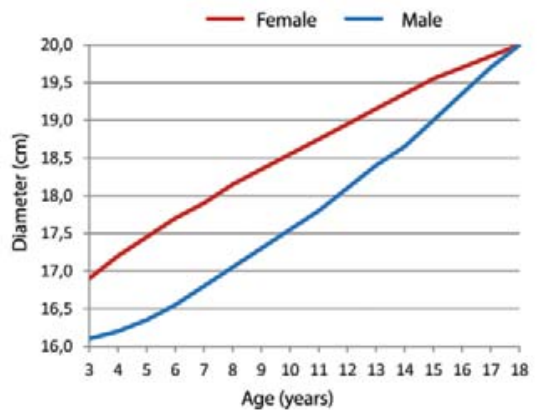

FIGURE 4: Size of giant congenital melanocytic nevus located on the head, according to the age 

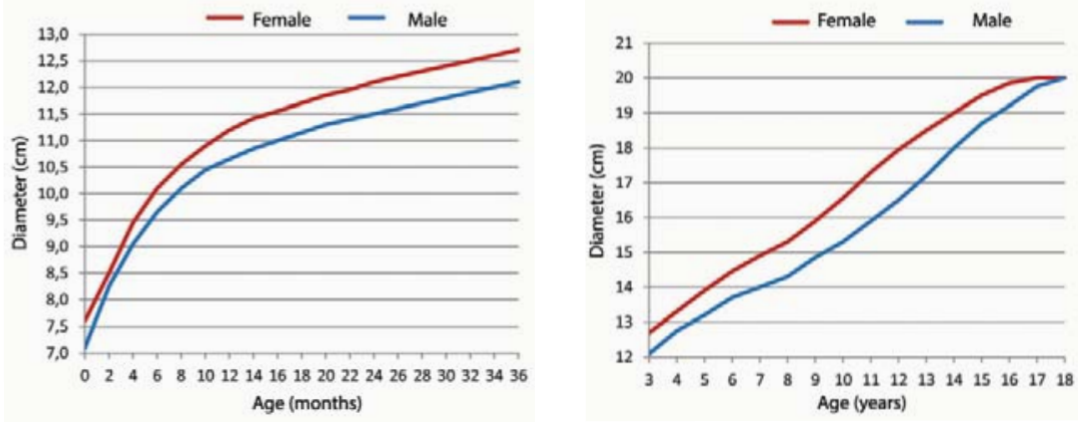

FIGURE 5: Size of giant congenital melanocytic nevus located on the body, according to the age

TABLE 1: Estimated size of CMN in adulthood based on its diameter in infancy

\begin{tabular}{lcc}
\hline CMN location on infant & CMN diameter at birth (cm)* & Factor $^{\dagger}$ \\
\hline Head & 11.8 & 1.7 \\
Hands, feet, torso, forearms, arms, hips & 7.2 & 2.8 \\
Thighs & 5.9 & 3.4 \\
Legs & 6.1 & 3.3 \\
\hline
\end{tabular}

CMN: Congenital melanocytic nevus.

* Diameter in which the nevus would reach at least $20 \mathrm{~cm}$ in adulthood.

† Factor that should be multiplied by the CMN diameter in infancy to obtain its estimated size in adulthood

Modified source: Marghoob et al. ${ }^{49}$

Among the findings that help differentiate CMN from acquired nevus are: presence of nevus cells in the lower two thirds of the dermis and subcutaneous tissue; arrangement of these cells as isolated elements or "in Indian line" among the collagen bundles of the lower reticular dermis; the involvement of sebaceous glands, blood vessels, erector muscles of hair follicles, eccrine glands and lymphatic vessels (typically, the nevus cells are present in many units and more than one cutaneous appendage, nerve or capillary vessel), and also the occurrence of perivascular, perifollicular and / or around the eccrine glands distribution, which often simulates inflammatory infiltrates. ${ }^{6,17,43,82}$ The involvement of collagen by nevus cells in the middle and deep reticular dermis is a CMN feature with high sensitivity (85.7\% to $98.3 \%$ ) and specificity $(72.5 \%$ to $96.7 \%)$. The finding of greater specificity, however, reaching $100 \%$, is the occurrence of nevus cells within the sebaceous glands, nerves and blood vessels in the deep reticular dermis. ${ }^{43,82}$

While these characteristics are present in CMN of all sizes, they are generally more pronounced in GCMN, to which they can be applied as diagnostic criteria with great accuracy. $17,20,36,83,84$

GCMN also presents a great variety of histological elements. In addition to the usual compound or intradermal melanocytic nevus pattern, other arrangements such as neural, blue nevus or Spitz nevus patterns may occur. In the neural subtype, there are areas of neuroid tissue differentiation - with microscopic structures formed by fibrillar collagen in an arrangement resembling Meissner corpuscles or Verocai bodies - and the lesion may resemble a neurofibroma. In the blue nevus GCMN type, cellular elements may resemble those of a common blue nevus or those from the cellular or giant nevus varieties. In the case of $\mathrm{CMN}$ with Spitz nevus features, there is a proliferation of spindle or epithelioid cells in the reticular dermis, which may associate to common nevus cells or neuroid cells, producing what is known as a combined nevus. ${ }^{6,17,43,51,5,85}$ The diversity of histological elements in GCMN could be explained by the fact that these lesions originate oftentimes from a pluripotent stem cell, which can differentiate into multiple cell types. ${ }^{1}$

Dermoscopy is a more useful tool for evaluating small to medium CMN. Regarding GCMN, its histological peculiarity of presenting nevus cells located deeper in the skin is one of the reasons for the low application of dermoscopy. Most giant nevi show a brownish homogeneous background with darker pigmentation islands. Other dermoscopic findings include hypertrichosis, perifollicular hypo or hyperpigmentation, pseudomilia and vascular structures. ${ }^{6.86}$

Complementary tests that aid in the diagnosis of NCM are magnetic resonance imaging (MRI) and cerebral spinal fluid (CSF) analysis. MRI is much more sensitive than CT for the detection of melanin, and it is the best method to evaluate the involvement of the 
leptomeninges. On examination, there is focal shortening of T1 relaxation time and, less frequently, of T2. $\mathrm{T} 1$ shortening can be seen without the use of contrast. The study of CSF rarely identifies melanocytic cells or free melanin. It is more usual to find low CSF glucose, high protein concentration and sterile leukocytosis. Cytological analysis of CSF, however, should not be performed for routine diagnosis. ${ }^{55,57-59,87,88}$

\section{EVOLUTION}

Over time, GCMN can undergo a process of darkening or lightening, develop a more heterogeneous or homogeneous pigmentation, present with an increase in hair growth, acquire a more irregular surface or, more rarely, spontaneously regress. ${ }^{7,4,89}$ Some authors observed an initial tendency to darkening of the lesions through adolescence, followed by a significant lightening, associated to an increase in surface roughness, appearance of nodules and hypertrichosis. ${ }^{24,46,90}$ Generally, lesions tend to become thicker over time. ${ }^{17,44-46}$ The appearance of nodules in the nevus usually corresponds to the proliferation of neuroid tissue elements. ${ }^{45,74}$

A major concern regarding patients with GCMN is the possibility of developing melanoma. Currently there is in the literature ample evidence that these individuals are at increased risk of developing the tumor. Although the value of the incidence rate of malignancies in GCMN may still be a matter of dispute, it is estimated that for these individuals the lifetime-risk for developing melanoma is between 5 and $10 \% \cdot{ }^{16,21,29,30}$ Although the probability that patients with GCMN develop melanoma throughout their life may seem small, the relative risk of the tumor in these patients compared to the general population, ranges from 52 to $2,600{ }^{15,16,18,1,9,24,25,49,81,91}$

Cutaneous melanoma that affects patients with GCMN presents some peculiarities. Unlike other melanomas that arise in the epidermis, the melanocytic neoplasia associated to GCMN has a non-epidermal origin in up to two thirds of cases, usually occurring in the dermis or in deeper layers., ${ }^{3,72,92}$

Cancerization can occur in extracutaneous melanocyte deposits, particularly in the CNS. The retroperitoneum and gastrointestinal tract mucosa may rarely be affected. ${ }^{4,19,93}$ In up to $24 \%$ of cases, the origin of melanoma can not be identified..$^{94}$ Dedavid et al. studied 289 patients with GCMN described in the literature and found 67 cases of melanoma, of which $50.7 \%$ appeared on the nevus; $3 \%$ were cutaneous melanomas, but originated in clinically normal skin; $31.3 \%$ were primary CNS tumors and $15 \%$ were metastatic tumors of unknown primary site. ${ }^{48}$

Some characteristics of patients with GCMN are associated with a higher risk of developing melanoma. Evidence points to an increased incidence of neoplasia in patients with multiple congenital satellite lesions and / or GCMN with a paravertebral or axial location, such as the back, neck or head. ${ }^{7,15,16,33,48}$

It is believed that the increased incidence of melanoma in individuals with GCMN - compared to those who have acquired nevi and small CMN - is explained by the significantly larger number of melanocytic cells or by a different biological behavior of melanocytes in GCMN. ${ }^{43,45,55,95-99}$ Changes in gene regulation associated with deoxyribonucleic acid repair mechanisms or tumor resistance to chemotherapy were observed in giant congenital melanocytic lesions. ${ }^{98}$ Furthermore, evidence has shown the importance of structural chromosomal abnormalities in the process of malignant transformation of these lesions. ${ }^{100}$

The probability that a patient diagnosed with GCMN develops melanoma is not constant throughout life and most evidence points to an increased risk in early childhood. ${ }^{5,46,48,49}$ Marghoob et al. reviewed the literature and found that about $70 \%$ of melanomas associated with GCMN were diagnosed before puberty, whereas less than $1 \%$ of all melanoma cases in the U.S. population occurs at this age. ${ }^{49}$ In a review conducted by Dedavid et al., which included 289 patients with GCMN, it was found that about $50 \%$ of melanomas were diagnosed before the age of five. ${ }^{48}$ Some recent studies, however, point out that the risk does not disappear during adulthood..$^{15,81,95}$

Other tumors, benign or malignant, can occur in patients with GCMN. These neoplasms often exhibit the same complex histology as seen on GCMN. Thus, the ambiguous tissue differentiation (with elements of melanocytic lineage and other neuroids, for example) can be present in tumors that originate in nevus, hindering the diagnosis. ${ }^{100,101}$

In the group of benign tumors, lipomas - sometimes of intraspinal location- are found as well as benign schwannomas..$^{54,62,102}$ Among tumors with some degree of malignancy, the following can be identified: malignant cellular blue nevus, minimal deviation melanomas, sarcomas, malignant schwannomas, liposarcomas and undifferentiated spindle cell neoplasms. ${ }^{30,92,101,103}$ Although mesenchymal elements (nonmelanocytic and non-neuroids) are rarely described in association with $\mathrm{CMN}$, it is known that sarcomas occur more frequently in patients with GCMN when compared to the general population. ${ }^{7,101}$

Particularly in the neonatal period, various types of melanocytic tumors may arise on GCMN, many of which are considered distinct from melanomas (although they often mimic this neoplasm). These proliferative lesions have varied sizes and can present rapid growth and ulceration. However, at this stage of life, even tumors with the 
most worrisome clinical features tend to have a benign behavior, showing stabilization (or regression) after a period of rapid growth..$^{80,92,100}$ Nodules appearing on GCMN in newborns can be very difficult to classify histologically, but despite the similarity with melanoma-simulating lesions, they usually show some maturation and do not exhibit the same degree of atypia or the high mitotic rate observed in malignant melanocytic neoplasms. Findings such as inflammatory infiltrate, cellular necrosis and perineural invasion are also suggestive of malignancy. ${ }^{13,17,80,100}$ Moreover, unlike melanoma, in which structural changes of chromosomes are found in most cases, the aberrations present in the benign proliferative nodules are predominantly numerical. ${ }^{100}$

Regarding NCM, the frequency of clinically manifested illness among patients with GCMN was estimated by literature reviews to be $4.5 \%$ to $11.4 \% .{ }^{78.104}$ Bittencourt et al., in their prospective study of 160 patients with GCMN, calculated at $2.5 \%$ the cumulative risk over five-years for the development of NCM in these individuals. ${ }^{19}$

Clinical manifestations of NCM occur most frequently in the first two years of life. They usually result from increased intracranial pressure secondary to obstruction of the ventricular system foramen, subarachnoid cistern or arachnoid granulations secondary to melanocytic proliferations. There may also be bleeding or, as suggested by the definition of the syndrome, cancerization of melanocytic cells. The neurological signs and symptoms include headache, lethargy, vomiting, irritability, increased head circumference, seizures, papilledema and occasionally cranial nerve palsies. Disease progression can lead to ataxia, or cause bladder and / or intestinal dysfunction. Severe and chronic psychosis is also described, especially when the disease manifests itself later. ${ }^{6,19,54,56-59,64,66,78,104,105}$

The hypothesis that there could be asymptomatic cases of NCM was confirmed after the development of MRI. Based on the analysis of resonances of patients at risk for developing NCM but without neurological signs or symptoms, it is estimated that at least $4.8 \%$ to $26 \%$ of these individuals may show characteristic alterations compatible with this syndrome during the exam..$^{19,59,66}$ The true prevalence of asymptomatic NCM in patients with GCMN, however, is still unknown, and there is little information about the clinical evolution of these patients. ${ }^{6,54}$

Studies show an association between the risk of NCM and three main features: the location of the CMN in the posterior axis (head, neck and paravertebral regions), greater number of satellite lesions and a large size nevus. . $^{16,58,64,78,105,106}$

\section{PROGNOSIS}

When melanoma arises in GCMN, the prognosis is especially dismal. Trozak et al., in their literature review that evaluated cases of childhood melanoma, observed that none of the 20 patients whose tumor was associated with GCMN was alive at the end of five years, whereas among 35 other individuals diagnosed with prepubertal melanoma (excluding cases of congenital neoplasm), the survival rate in the same period was $34.3 \%{ }^{46}$

There are some explanations for this unfavorable evolution. The fact that cutaneous melanoma associated with GCMN typically grows in the dermis makes it more difficult to detect in clinical exams. Unlike the malignant transformation that occurs in small or medium CMN, starting at the dermal-epidermal junction, and thus rapidly changing the appearance of a nevus, in the case of GCMN it is often necessary that a large nodule develops or ulceration occurs before the diagnosis of cancer is made. ${ }^{11,55,107}$ Moreover, the often rough or nodular surface of GCMN further complicates the early observation of the tumor ${ }^{46,72}$ Another factor that may contribute to the severity of the disease is the great extent of nevic lesions (commonly crossing the midline), which causes their lymphatic drainage to be performed by multiple channels. Moreover, the presence of malignant cells in the deeper layers of the nevus facilitates tumoral spread through the lymph and blood vessels of greater caliber, favoring the occurrence of early metastases. ${ }^{46}$ Besides, the occurrence of the disease in extracutaneous sites may contribute to the delay in its recognition. The difficult clinical detection of the tumor contributes to the fact that in $24 \%$ of cases, melanoma will already be metastatic at the time of diagnosis without the primary site being identified. ${ }^{94}$

Prognosis of symptomatic NCM is also poor. More than half of the patients will die within three years after the onset of symptoms and $70 \%$ before 10 years of age. The median age at death is 4.5 years. ${ }^{19,57,58,7,7,104}$ The use of chemotherapy and radiation therapy are not effective in modifying the course of the disease. Palliative treatments, such as the use of shunts to reduce intracranial pressure and administration of anticonvulsants may however be used..$^{55,57,58,104}$

\section{TREATMENT}

The approach to GCMN represents a challenge and should be individualized taking into consideration: age of the patient, size and location of the lesion, risk of melanoma, possibility of concomitant NCM; presence of changes suggestive of malignancy on the nevus; possible functional impairments resulting from 
invasive procedures and the psychological impact associated with $\mathrm{CMN}$ or the surgical scars, often unsightly. Thus, treatment of patients with GCMN may include surgical or non-surgical procedures, psychological and / or clinical interventions, with the utmost attention in changes of color, texture or in the surface of the lesion. ${ }^{6,7,28,103}$

The decision of whether or not a patient should undergo surgical treatment involves both the technical difficulties of performing such procedures (especially when considering the cosmetic motivations) and the uncertainties regarding its effectiveness as a prophylaxis against melanoma.

The recommendation of prophylactic surgical excision would be justified based on the assumption that melanoma may arise on the nevic lesion. However, as seen earlier, $50 \%$ of melanomas found in patients with GCMN occur elsewhere. ${ }^{16,48}$ Therefore, the removal of the nevus does not guarantee protection against malignancy. In addition, the size of "garment" GCMN may prevent the complete resection (Figure 6). It is difficult to measure the impact of total excision of GCMN or other therapeutic measures on the risk of developing melanoma. Probably the reduction of melanocytic cells reduces the incidence of malignancy. However, the heterogeneity of the studies that evaluated the different types of treatment used and their extension prevents a quantitative analysis, so that there is no current evidence that the removal of the nevus has a prophylactic role against the onset of

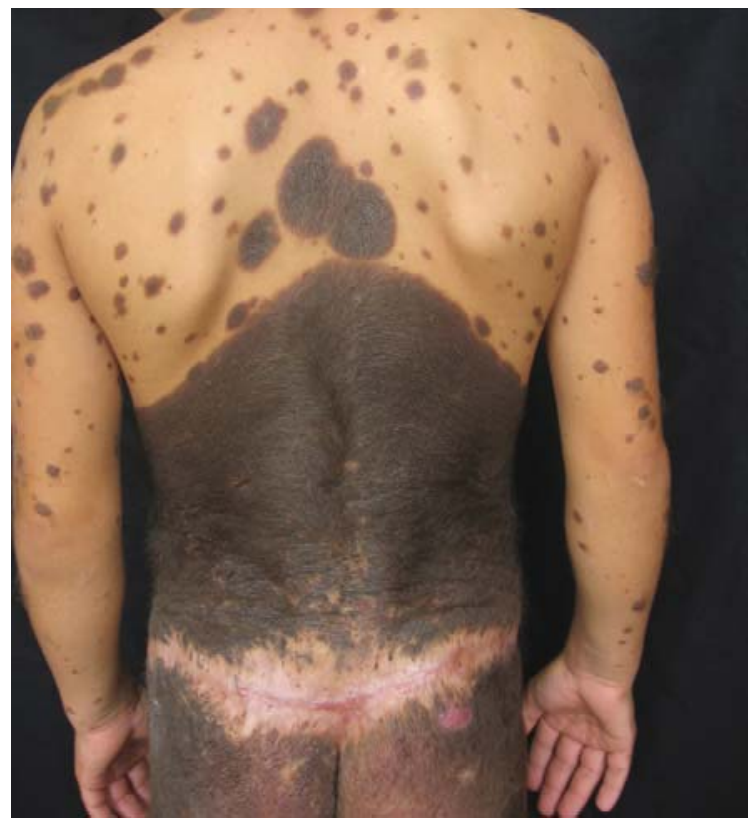

FIGURE 6: Giant congenital melanocytic nevus "in bathing trunk" submitted to partial surgical removal melanoma. ${ }^{15,29,97,105,108}$ For these reasons, the more aggressive approach to GCMN remains controversial. ${ }^{13,23}$ Some authors suggest considering prophylactic excision for the more heterogeneous, thick or rough lesions, or for those that for any other reason are difficult to follow clinically. ${ }^{103,107}$

The size of the lesions makes their removal often dependent on the use of tissue expanders (especially for nevi located on the head or neck), serial interventions, the use of skin flaps, grafts or a combination of more than one type of surgical procedure. ${ }^{13,50,68,73,75,103,109-112}$ Postoperative complications include contractures (which can cause functional alterations), requiring the removal of the grafts used to cover the primary defects, seromas (especially in cases where tissue expanders are used), hematomas, infection, ischemic skin flaps, suture dehiscence and formation of keloids. ${ }^{13,68,109,111,112}$ Although various surgical techniques are described for the treatment of GCMN, none is universally accepted. ${ }^{13,30}$ More recently, synthetic skin substitutes have been used in some cases to treat the defects secondary to the removal of GCMN. ${ }^{13,109}$ However, there are no studies evaluating this technique on large samples and results were inferior to those obtained with the use of tissue expanders. ${ }^{13}$

The partial removal of GCMN by procedures such as dermabrasion, skin curettage, tangential excision (shave excision), chemical peels and laser treatment has mostly cosmetic purposes, since only the most superficial cells of the lesion are removed. , $^{6,13,27,37,49}$

Dermabrasion and skin curettage are most efficient if performed in the first two to six weeks of life, when it is easier to find a cleavage plan between the upper dermis, rich in nevic cells, and the deeper dermis, relatively poor in these cells. ${ }^{11,113,114}$

Dermabrasion may cause permanent (if performed early) or transient reduction in the pigmentation of the nevus, but it is not able to completely treat hypertrichosis. ${ }^{37,115-117}$ The procedure is performed under general anesthesia, and infection is the main adverse event described. There is also the risk of tissue loss requiring skin-grafting when dermabrasion reaches the deeper layers of the skin. ${ }^{115,117}$

Studies have reported good cosmetic results after curettage. This is a procedure that can be performed in one session, in contrast to what usually happens with surgical excision. However, this approach also carries the risks of general anesthesia and the authors describe complications such as hypertrophic scars and infection. Furthermore, repigmentation of the treated area usually occurs partially. ${ }^{113,114,118}$

Tangential excision of the upper dermis may cause mild scarring, sometimes with dotted pigmentation, in infants less than nine weeks old. In older 
children, however, the cosmetic results are worse. The procedure can be combined with excision of the thickened portion of the nevus. ${ }^{42,93}$

Chemical peels can improve the appearance of lighter GCMN or those whose nevus cells are more superficially located. ${ }^{103,119}$ Ruiz-Maldonado et al. used phenol peeling (Baker's formula) for the cosmetic treatment of patients who did not want or were not good candidates for surgical treatment. ${ }^{27}$ Larger nevi were treated in multiple sessions in order to avoid the cardiac and renal toxic effects of phenol. Scars were the most common complication, usually secondary to the occurrence of infection. The less toxic trichloroacetic acid at $50 \%$ concentration has also been used for depigmentation purposes in this study. Hopkins et al. treated 20 patients with the phenol solution and obtained good results in $75 \%$ of cases. No complications were observed. ${ }^{119}$

The use of laser in the treatment of GCMN is controversial. Lasers that can be used for this purpose are ruby, Q-switched, and carbon dioxide lasers (which can be combined with Q-switched ruby lasers or Nd:YAG). However, though they may improve the aesthetic appearance of some lesions and reduce the number of melanocytic cells, there is some concern that nevus cells exposed to sublethal doses of energy may have a higher probability of malignant transformation. Repigmentation may also occur. Thus, it is recommended to consider using the laser only when an interventional approach is the choice and surgical treatment is not feasible..$^{23,120}$

There is also a discussion whether the techniques that partially remove congenital pigmented lesions could impair or facilitate the detection of abnormalities suggestive of melanoma on the nevus. ${ }^{7,13,23,11,118}$ However, there is no doubt that in the event of unwanted hypertrophic or sclerotic scars over the treated area, a possible diagnosis of melanoma originated from the deep dermis or subcutaneous tissue may be delayed. ${ }^{103}$ Furthermore, it may be difficult to distinguish between an area of malignancy and a pseudomelanoma (recurrent nevus originated after the incomplete removal of nevic cells) in those GCMN treated with one of these procedures. ${ }^{7,37,103,115,121}$

Even with these caveats, one can consider - to achieve cosmetic goals - alternative therapeutic modalities (such as skin curettage, dermabrasion and chemical peels) instead of surgeries, considering: the often poor aesthetic results of surgeries, the lengthy process necessary to remove a GCMN, involving multiple steps and requiring the use of tissue expanders and extensive grafts, and the high-cost of these treatments. ${ }^{27,108}$
On the other hand, some authors who advocate the removal of GCMN aiming at prophylaxis against melanoma also believe that the excision should occur early on, taking into account not only the increased risk of malignancy in early childhood ${ }^{50,75,81}$ but also the possibility of obtaining more satisfactory cosmetic results, due to better healing, when operating in this age group. ${ }^{75,103}$ Other studies contradict this recommendation. Kinsler \& Bulstrode ${ }^{97}$ argue that studies that advocate the early intervention are based on a small number of cases and did not compare these results with those of children who were operated at an older age. Kinsler et al., in a prospective cohort consisting of 122 patients with GCMN, did not observe any significant clinical or aesthetical differences between children operated at one, five or 10 years of age. ${ }^{122}$ On the other hand, there is evidence that infants under one year of age have a higher risk of cardiac arrest due to anesthesia. ${ }^{123,124}$ In addition, there are studies that point to potential neurological damages and learning difficulties in children undergoing procedures with general anesthesia as infants. ${ }^{6,125}$

Despite the controversy about the treatment, it is a consensus that the only absolute indication for surgical intervention in GCMN is the emergence of a malignant neoplasm on the lesion..$^{6,11,103}$

It is known, however, that clinical follow-up of GCMN also has its difficulties, given the tendency of the surface of the lesion to have irregularities and nodules, and often a darken coloration and hypertrichosis. ${ }^{3,17,24}$ Therefore, patients and / or their parents should be instructed to perform regular self-examination of skin and anticipate the medical consultation in case there are changes of color, shape, surface or appearance of the nevus or also other abnormal symptoms. The follow-up of patients becomes easier when performed by a multidisciplinary team, including dermatologist, plastic surgeon, radiologist and also with access to psychologists and neurologists, if necessary. During the periodic examination, it is important to perform the palpation of the lesion and lymph nodes. Serial photographs facilitate the monitoring of the evolution of GCMN. ${ }^{6,11,23,97}$

Taking into consideration the risk of extracutaneous melanomas, in the skin area outside the GCMN or even very deeply under the lesion, it is important to note that even patients whose nevus was completely removed must undergo lifelong, regular examinations of all skin and general medical examination, to facilitate the detection of any malignancy in its earliest stages. ${ }^{6,49,97}$ 


\section{REFERENCES}

1. Grichnik JM, Rhodes AR, Sober AJ. Benign neoplasias and hyperplasias of melanocytes. In: Wolff K, Goldsmith LA, Katz SI, Gilchrest BA, Paller AS, Lefell DJ, editors. Fitzpatrick's Dermatology in General Medicine. 7th ed. New York: McGrawHill; 2008. p. 1099-122.

2. Kincannon J, Boutzale C. The physiology of pigmented nevi. Pediatrics. 1999;104:1042-5.

3. Rhodes AR. Melanocytic precursors of cutaneous melanoma. Estimated risks and guidelines for management. Med Clin North Am. 1986;70:3-37.

4. Arneja J, Gosain A. Giant congenital melanocytic nevi. Plast Reconstr Surg. 2007;120:26e-40e.

5. Kaplan EN. The risk of malignancy in large congenital nevi. Plast Reconstr Surg. 1974:53:421-8.

6. Kovalyshyn I, Braun R, Marghoob A. Congenital melanocytic naevi. Australas J Dermatol. 2009;50:231-40.

7. Marghoob AA. Congenital melanocytic nevi. Evaluation and management. Dermatol Clin. 2002;20:607-16, viii.

8. Mizushima J, Nogita T, Higaki Y, Horikoshi T, Kawashima M. Dormant melanocytes in the dermis: do dermal melanocytes of acquired dermal melanocytosis exist from birth? Br J Dermatol. 1998;139:349-50.

9. Rhodes AR. Congenital nevomelanocytic nevi. Histologic patterns in the first year of life and evolution during childhood. Arch Dermatol. 1986;122:1257-62.

10. Wu D, Wang M, Wang X, Yin N, Song T, Li H, et al. Lack of BRAF(V600E) mutations in giant congenital melanocytic nevi in a Chinese population. Am J Dermatopathol.2011;33:341-4.

11. Slutsky JB, Barr JM, Femia AN, Marghoob AA. Large congenital melanocytic nevi: associated risks and management considerations. Semin Cutan Med Surg.2010;29:79-84

12. Kinsler VA, Birley J, Atherton DJ. Great Ormond Street Hospital for Children Registry for congenital melanocytic naevi: prospective study 1988-2007. Part 1epidemiology, phenotype and outcomes. Br J Dermatol. 2009;160:143-50.

13. Arneja J, Gosain A. Giant congenital melanocytic nevi. Plast Reconstr Surg. 2009:124:1e-13e.

14. Strauss RM, Newton Bishop JA. Spontaneous involution of congenital melanocytic nevi of the scalp. J Am Acad Dermatol. 2008:58:508-11.

15. Krengel S, Hauschild A, Schäfer T. Melanoma risk in congenital melanocytic naevi: a systematic review. Br J Dermatol. 2006;155:1-8.

16. Hale E, Stein J, Ben-Porat L, Panageas K, Eichenbaum M, Marghoob A, et al. Association of melanoma and neurocutaneous melanocytosis with large congenital melanocytic naevi--results from the NYU-LCMN registry. $\mathrm{Br} J$ Dermatol. 2005;152:512-7.

17. Tannous Z, Mihm MJ, Sober A, Duncan L. Congenital melanocytic nevi: clinical and histopathologic features, risk of melanoma, and clinical management. J Am Acad Dermatol. 2005;52:197-203.

18. Watt AJ, Kotsis SV, Chung KC. Risk of melanoma arising in large congenital melanocytic nevi: a systematic review. Plast Reconstr Surg.2004;113:1968-74.

19. Bittencourt F, Marghoob A, Kopf A, Koenig K, Bart R. Large congenital melanocytic nevi and the risk for development of malignant melanoma and neurocutaneous melanocytosis. Pediatrics. 2000;106:736-41.

20. Kopf A, Bart R, Hennessey P. Congenital nevocytic nevi and malignant melanomas. J Am Acad Dermatol. 1979;1:123-30.

21. Marghoob AA, Bittencourt FV, Kopf AW, Bart RS. Large congenital melanocytic nevi. Curr Probl Dermatol. 2000;12:146-52.

22. Koot HM, de Waard-van der Spek F, Peer CD, Mulder PG, Oranje AP. Psychosocial sequelae in 29 children with giant congenital melanocytic naevi. Clin Exp Dermatol. 2000;25:589-93.

23. Marghoob AA, Borrego JP, Halpern AC. Congenital melanocytic nevi: treatment modalities and management options. Semin Cutan Med Surg. 2007;26:231-40.

24. Egan CL, Oliveria SA, Elenitsas R, Hanson J, Halpern AC. Cutaneous melanoma risk and phenotypic changes in large congenital nevi: a follow-up study of 46 patients. J Am Acad Dermatol. 1998;39:923-32.

25. Swerdlow AJ, English JS, Qiao Z. The risk of melanoma in patients with congenital nevi: a cohort study. J Am Acad Dermatol. 1995;32:595-9.

26. Greeley PW, Middleton AG, Curtin JW. Incidence of malignancy in giant pigmented nevi. Plast Reconstr Surg. 1965;36:26-37.

27. Ruiz-Maldonado R, Tamayo L, Laterza AM, Durán C. Giant pigmented nevi: clinical, histopathologic, and therapeutic considerations. J Pediatr. 1992;120:906-11.

28. Quaba AA, Wallace AF. The incidence of malignant melanoma ( 0 to 15 years of age) arising in "large" congenital nevocellular nevi. Plast Reconstr Surg. 1986;78:174-81.

29. Ka VS, Dusza SW, Halpern AC, Marghoob AA. The association between large congenital melanocytic naevi and cutaneous melanoma: preliminary findings from an Internet-based registry of 379 patients. Melanoma Res. 2005;15:61-7.
30. Zaal L, Mooi W, Sillevis Smitt J, van der Horst C. Classification of congenital melanocytic naevi and malignant transformation: a review of the literature. $\mathrm{Br} \mathrm{J}$ Plast Surg. 2004;57:707-19.

31. Walton RG, Jacobs $A H$, Cox AJ. Pigmented lesions in newborn infants. $\mathrm{Br} \mathrm{J}$ Dermatol. 1976;95:389-96.

32. Castilla EE, da Graça Dutra M, Orioli-Parreiras IM. Epidemiology of congenital pigmented naevi: I. Incidence rates and relative frequencies. $\mathrm{Br} J$ Dermatol. 1981;104:307-15.

33. Bett B. Large or multiple congenital melanocytic nevi: occurrence of cutaneous melanoma in 1008 persons. J Am Acad Dermatol.2005;52:793-7.

34. Takayama H, Nagashima $\mathrm{Y}$, Hara M, Takagi H, Mori M, Merlino G, et al. Immunohistochemical detection of the c-met proto-oncogene product in the congenital melanocytic nevus of an infant with neurocutaneous melanosis. J Am Acad Dermatol.2001;44:538-40.

35. Saida T. Histogenesis of congenital and acquired melanocytic nevi: a unifying concept. Am J Dermatopathol. 2006;28:377-9.

36. Cribier BJ, Santinelli F, Grosshans E. Lack of clinical-pathological correlation in the diagnosis of congenital naevi. Br J Dermatol. 1999;141:1004-9.

37. Zitelli JA, Grant MG, Abell E, Boyd JB. Histologic patterns of congenital nevocytic nevi and implications for treatment. J Am Acad Dermatol. 1984;11:402-9.

38. Takayama H, LaRochelle WJ, Sharp R, Otsuka T, Kriebel P, Anver M, et al. Diverse tumorigenesis associated with aberrant development in mice overexpressing hepatocyte growth factor/scatter factor. Proc Natl Acad Sci U S A.1997;94:701-6.

39. Takayama H, La Rochelle WJ, Anver M, Bockman DE, Merlino G. Scatter factor/hepatocyte growth factor as a regulator of skeletal muscle and neural crest development. Proc Natl Acad Sci U S A.1996;93:5866-71.

40. Luo R, Gao J, Wehrle-Haller B, Henion PD. Molecular identification of distinct neurogenic and melanogenic neural crest sublineages. Development.2003;130:321-30.

41. Herron MD, Vanderhooft SL, Smock K, Zhou H, Leachman SA, Coffin C. Proliferative nodules in congenital melanocytic nevi: a clinicopathologic and immunohistochemical analysis. Am J Surg Pathol. 2004;28:1017-25.

42. Sandsmark M, Eskeland G, Ogaard AR, Abyholm F, Clausen OP. Treatment of large congenital naevi.A review and report of six cases.Scand J Plast Reconstr Surg Hand Surg. 1993;27:223-32.

43. Mark GJ, Mihm MC, Liteplo MG, Reed RJ, Clark WH. Congenital melanocytic nevi of the small and garment type. Clinical, histologic, and ultrastructural studies. Hum Pathol. 1973:4:395-418

44. Dawson HA, Atherton DJ, Mayou B. A prospective study of congenital melanocytic naevi: progress report and evaluation after 6 years. $\mathrm{Br} \mathrm{J}$ Dermatol. 1996;134:617-23.

45. From L. Congenital nevi--let's be practical. Pediatr Dermatol. 1992;9:345-6.

46. Trozak DJ, Rowland WD, Hu F. Metastatic malignant melanoma in prepubertal children. Pediatrics. 1975;55:191-204.

47. Arneja JS, Gosain AK.Giant congenital melanocytic nevi of the trunk and an algorithm for treatment. J Craniofac Surg.2005;16:886-93.

48. DeDavid M, Orlow SJ, Provost N, Marghoob AA, Rao BK, Huang CL, et al. A study of large congenital melanocytic nevi and associated malignant melanomas: review of cases in the New York University Registry and the world literature. J Am Acad Dermatol. 1997;36:409-16.

49. Marghoob AA, Schoenbach SP, Kopf AW, Orlow SJ, Nossa R, Bart RS. Large congenital melanocytic nevi and the risk for the development of malignant melanoma. A prospective study.Arch Dermatol. 1996;132:170-5.

50. Turkmen A, Isik D, Bekerecioglu M. Comparison of classification systems for congenital melanocytic nevi. Dermatol Surg.2010;36:1554-62.

51. Reed WB, Becker SW, Nickel WR. Giant pigmented nevi, melanoma, and leptomeningeal melanocytosis: a clinical and histopathological study. Arch Dermatol. 1965:91:100-19.

52. Feng J, Sethi A, Reyes-Múgica M, Antaya R. Life-threatening blood loss from scratching provoked by pruritus in the bulky perineal nevocytoma variant of giant congenital melanocytic nevus in a child.J Am Acad Dermatol. 2005;53:S139-42.

53. Giam YC, Williams ML, Leboit PE, Orlow SJ, Eichenfield LF, Frieden IJ. Neonatal erosions and ulcerations in giant congenital melanocytic nevi. Pediatr Dermatol. 1999;16:354-8.

54. Price $\mathrm{H}$, Schaffer J. Congenital melanocytic nevi-when to worry and how to treat: Facts and controversies. Clin Dermatol. 2010;28:293-302.

55. Shah KN. The risk of melanoma and neurocutaneous melanosis associated with congenital melanocytic nevi. Semin Cutan Med Surg. 2010;29:159-64.

56. Makkar HS, Frieden IJ. Neurocutaneous melanosis. Semin Cutan Med Surg. 2004;23:138-44

57. Martínez-Granero MA, Pascual-Castroviejo I. Neurocutaneous melanosis. Rev Neurol. 1997;25:S265-8. 
58. Kadonaga JN, Frieden IJ. Neurocutaneous melanosis: definition and review of the literature. J Am Acad Dermatol. 1991;24:747-55.

59. Frieden IJ, Williams ML, Barkovich AJ. Giant congenital melanocytic nevi: brain magnetic resonance findings in neurologically asymptomatic children. J Am Acad Dermatol. 1994;31:423-9.

60. Chung C, Forte A, Narayan D, Persing J. Giant nevi: a review. J Craniofac Surg. 2006;17:1210-5.

61. Caradona SA, Skidmore R, Gupta A, Bush CH, Ford MJ. Giant congenital melanocytic nevus with underlying hypoplasia of the subcutaneous fat. Pediatr Dermatol. 2000;17:387-90.

62. Wieselthaler NA, van Toorn R, Wilmshurst JM. Giant congenital melanocytic nevi in a patient with brain structural malformations and multiple lipomatosis. J Child Neurol. 2002;17:289-91.

63. Itin PH, Lautenschlager S. Lower and upper extremity atrophy associated with a giant congenital melanocytic nevus. Pediatr Dermatol. 1998;15:287-9.

64. Lovett A, Maari C, Decarie JC, Marcoux D, McCuaig C, Hatami A, et al. Large congenital melanocytic nevi and neurocutaneous melanocytosis: one pediatric center's experience. J Am Acad Dermatol. 2009;61:766-74.

65. Itin PH, Lautenschlager S. Acquired leukoderma in congenital pigmented nevus associated with vitiligo-like depigmentation. Pediatr Dermatol. 2002;19:73-5.

66. Foster RD, Williams ML, Barkovich AJ, Hoffman WY, Mathes SJ, Frieden IJ. Giant congenital melanocytic nevi: the significance of neurocutaneous melanosis in neurologically asymptomatic children. Plast Reconstr Surg. 2001;107:933-41.

67. Ruiz-Maldonado R. Measuring congenital melanocytic nevi. Pediatr Dermatol. 2004 2004:21:178-9.

68. Lanier VC Jr, Pickrell KL, Georgiade NG. Congenital giant nevi: clinical and pathological considerations. Plast Reconstr Surg. 1976;58:48-54.

69. Pers M. Naevus pigmentosus giganticus: indikationer for operative Behandling. Ugeskr Laeger. 1963;125:613-9.

70. Illig L, Weidner F, Hundeiker M, Gartmann H, Biess B, Leyh F, et al. Congenital nevi less than or equal to $10 \mathrm{~cm}$ as precursors to melanoma. 52 cases, a review, and a new conception. Arch Dermatol. 1985;121:1274-81.

71. Lorentzen M, Pers M, Bretteville-Jensen G. The incidence of malignant transformation in giant pigmented nevi. Scand J Plast Reconstr Surg.1977;11:163-7.

72. Rhodes AR, Wood WC, Sober AJ, Mihm MC. Nonepidermal origin of malignant melanoma associated with a giant congenital nevocellular nevus. Plast Reconstr Surg. 1981;67:782-90

73. Arons MS, Hurwitz S. Congenital nevocellular nevus: a review of the treatment controversy and a report of 46 cases. Plast Reconstr Surg. 1983;72:355-65.

74. Solomon L, Eng AM, Bené M, Loeffel ED. Giant congenital neuroid melanocytic nevus. Arch Dermatol. 1980;116:318-20.

75. Bauer BS, Vicari FA. An approach to excision of congenital giant pigmented nevi in infancy and early childhood. Plast Reconstr Surg. 1988;82:1012-21.

76. Rhodes AR, Albert LS, Weinstock MA. Congenital nevomelanocytic nevi: proportionate area expansion during infancy and early childhood. J Am Acad Dermatol. 1996;34:51-62.

77. Enhamre A. Congenital nevi: accuracy of relative area index measurements. Arch Dermatol. 1987;123:709-10.

78. DeDavid M, Orlow SJ, Provost N, Marghoob AA, Rao BK, Wasti Q, et al. Neurocutaneous melanosis: clinical features of large congenital melanocytic nevi in patients with manifest central nervous system melanosis. J Am Acad Dermatol.1996;35:529-38.

79. Enhamre A. Relative area index in congenital nevi. Arch Dermatol. 1986;122:501-2.

80. Barnhill RL, Chastain MA, Jerdan MS, Lebbé C, Janin A, Lugassy C. Angiotropic neonatal congenital melanocytic nevus: how extravascular migration of melanocytes may explain the development of congenital nevi. Am J Dermatopathol. 2010;32:495-9.

81. Zaal LH, Mooi WJ, Klip H, van der Horst CM. Risk of malignant transformation of congenital melanocytic nevi: a retrospective nationwide study from The Netherlands. Plast Reconstr Surg. 2005;116:1902-9.

82. Rhodes AR, Silverman RA, Harrist TJ, Melski JW. A histologic comparison of congenital and acquired nevomelanocytic nevi. Arch Dermatol. 1985;121:1266-73

83. Barnhill RL, Fleischli M. Histologic features of congenital melanocytic nevi in infants 1 year of age or younger. J Am Acad Dermatol. 1995;33:780-5.

84. Everett MA. Histopathology of congenital pigmented nevi. Am J Dermatopathol. 1989;11:11-2.

85. Silfen R, Skoll PJ, Hudson DA. Congenital giant hairy nevi and neurofibromatosis: the significance of their common origin. Plast Reconstr Surg. 2002;110:1364-5.

86. Changchien L, Dusza SW, Agero AL, Korzenko AJ, Braun RP, Sachs D, et al. Ageand site-specific variation in the dermoscopic patterns of congenital melanocytic nevi: an aid to accurate classification and assessment of melanocytic nevi. Arch Dermatol.2007;143:1007-14.
87. D'Argenio A, David P, Engohan C, Hennequin $Y$, Balériaux D, Jissendi $P$. Neurocutaneous melanosis in a newborn with giant congenital melanocytic nevus. J Neuroradiol. 2007:34:272-5.

88. Bett B. Large or multiple congenital melanocytic nevi: occurrence of neurocutaneous melanocytosis in 1008 persons. J Am Acad Dermatol. 2006;54:767-77.

89. Gass JK, Grant JW, Hall PN, Atherton DJ, Burrows NP. Clinical resolution of a neonatally eroded giant congenital melanocytic nevus.Pediatr Dermatol. 2006;23:567-70.

90. Pack GT, Davis J. Nevus giganticus pigmentosus with malignant transformation. Surgery. 1961;49:347-54.

91. Viana ACL. Risco de desenvolvimento de melanoma em pacientes portadores de nevo melanocítico congênito gigante [dissertação] (Risk of development of melanoma in patients with giant congenital melanocytic nevus [dissertation]). Belo Horizonte (MG): Universidade Federal de Minas Gerais; 2012. 122 p.

92. Phadke PA, Rakheja D, Le LP, Selim MA, Kapur P, Davis A, et al. Proliferative nodules arising within congenital melanocytic nevi: a histologic, immunohistochemical, and molecular analyses of 43 cases. Am J Surg Pathol.2011;35:656-69.

93. Lawrence CM. Treatment options for giant congenital naevi. Clin Exp Dermatol. 2000;25:7-11.

94. Marghoob AA, Schoenbach SP, Kopf AW, Orlow SJ, Nossa R, Bart RS. Large congenital melanocytic nevi and the risk for the development of malignant melanoma: a prospective study. J Invest Dermatol. 1995;104:563.

95. Hernández A, Torrelo A. Recent data on the risk of malignancy in congenital melanocytic nevi: the continuing debate on treatment. Actas Dermosifiliogr. 2008;99:185-9.

96. Berg P, Lindelöf B. Congenital melanocytic naevi and cutaneous melanoma. Melanoma Res.2003;13:441-5.

97. Kinsler V, Bulstrode N. The role of surgery in the management of congenital melanocytic naevi in children: a perspective from Great Ormond Street Hospital. J Plast Reconstr Aesthet Surg. 2009;62:595-601.

98. Dessars B, De Raeve LE, Morandini R, Lefort A, El Housni H, Ghanem GE,et al Genotypic and gene expression studies in congenital melanocytic nevi: insight into initial steps of melanotumorigenesis. J Invest Dermatol.2009;129:139-47.

99. Dasu MR, Barrow RE, Hawkins HK, McCauley RL. Gene expression profiles of giant hairy naevi. J Clin Pathol.2004;57:849-55.

100. Bastian BC, Xiong J, Frieden IJ, Williams ML, Chou P, Busam K, et al. Genetic changes in neoplasms arising in congenital melanocytic nevi: differences between nodular proliferations and melanomas. Am J Pathol.2002;161:1163-9.

101. Hendrickson MR, Ross JC. Neoplasms arising in congenital giant nevi: morphologic study of seven cases and a review of the literature. Am J Surg Pathol. 1981;5:109-35.

102. Bae JM, Kim MY, Kim HO, Park YM. Schwannoma coexisting with giant congenital melanocytic nevus: is it coincidence? J Am Acad Dermatol. 2007;56:S111-2.

103. Tromberg J, Bauer B, Benvenuto-Andrade C, Marghoob AA. Congenital melanocytic nevi needing treatment. Dermatol Ther.2005;18:136-50.

104. Agero AL, Benvenuto-Andrade C, Dusza SW, Halpern AC, Marghoob AA. Asymptomatic neurocutaneous melanocytosis in patients with large congenital melanocytic nevi: a study of cases from an Internet-based registry. J Am Acad Dermatol. 2005;53:959-65.

105. Kinsler VA, Chong WK, Aylett SE, Atherton DJ. Complications of congenital melanocytic naevi in children: analysis of 16 years' experience and clinical practice. $\mathrm{Br}$ J Dermatol. 2008;159:907-14.

106. Marghoob AA, Dusza S, Oliveria S, Halpern AC. Number of satellite nevi as a correlate for neurocutaneous melanocytosis in patients with large congenital melanocytic nevi. Arch Dermatol. 2004;140:171-5.

107. Marghoob AA, Agero AL, Benvenuto-Andrade C, Dusza SW. Large congenital melanocytic nevi, risk of cutaneous melanoma, and prophylactic surgery. J Am Acad Dermatol. 2006;54:868-70.

108. Kanzler MH. Management of large congenital melanocytic nevi: art versus science. J Am Acad Dermatol. 2006;54:874-6.

109. Warner P, Yakuboff K, Kagan R, Boyce S, Warden G. An 18-year experience in the management of congenital nevomelanocytic nevi. Ann Plast Surg. 2008;60:283-7.

110. Gosain AK, Santoro TD, Larson DL, Gingrass RP. Giant congenital nevi: a 20-year experience and an algorithm for their management. Plast Reconstr Surg. 2001;108:622-36.

111. Chrétien-Marquet B, Bennaceur S, Fernandez R. Surgical treatment of large cutaneous lesions of the back in children by concentric cutaneous mobilization. Plast Reconstr Surg. 1997:100:926-36.

112. Carneiro LVFJ, Aguiar LFS, Pitanguy I. Tratamento cirúrgico do nevo melanocítico gigante. Rev Bras Cir Plast. 2011;26:198-204.

113. De Raeve LE, De Coninck AL, Dierickx PR, Roseeuw DI. Neonatal curettage of giant congenital melanocytic nevi. Arch Dermatol. 1996;132:20-2.

114. Moss AL. Congenital "giant" naevus: a preliminary report of a new surgical approach. Br J Plast Surg. 1987;40:410-9. 
115. Bohn J, Svensson H, Aberg M. Dermabrasion of large congenital melanocytic naevi in neonates. Scand J Plast Reconstr Surg Hand Surg.2000;34:321-6.

116. Gari LM, Rivers JK, Kopf AW. Melanomas arising in large congenital nevocytic nevi: a prospective study. Pediatr Dermatol. 1988;5:151-8.

117. Miller CJ, Becker DW Jr. Removing pigmentation by dermabrading naevi in infancy.Br J Plast Surg. 1979;32:124-6.

118. De Raeve LE, Roseeuw DI. Curettage of giant congenital melanocytic nevi in neonates: a decade later. Arch Dermatol. 2002;138:943-7.

119. Hopkins JD, Smith AW, Jackson IT. Adjunctive treatment of congenital pigmented nevi with phenol chemical peel.Plast Reconstr Surg.2000;105:1-11.

120. Michel JL. Laser therapy of giant congenital melanocytic nevi. Eur J Dermatol. 2003 2003;13:57-64.

121. Dummer R, Kempf W, Burg G. Pseudo-melanoma after laser therapy. Dermatology. 1998;197:71-3.

122. Kinsler VA, Birley J, Atherton DJ. Great Ormond Street Hospital for Children Registry for Congenital Melanocytic Naevi: prospective study 1988-2007. Part 2-Evaluation of treatments. Br J Dermatol. 2009;160:387-92.

123. Braz LG, Módolo NS, do Nascimento P Jr, Bruschi BA, Castiglia YM, Ganem EM,et al. Perioperative cardiac arrest: a study of 53,718 anaesthetics over 9 yr from a Brazilian teaching hospital. Br J Anaesth.2006;96:569-75.

124. Morray JP, Geiduschek JM, Ramamoorthy C, Haberkern CM, Hackel A, Caplan RA et al. Anesthesia-related cardiac arrest in children: initial findings of the Pediatric Perioperative Cardiac Arrest (POCA) Registry. Anesthesiology. 2000;93:6-14.

125. Loepke AW, Soriano SG. An assessment of the effects of general anesthetics on developing brain structure and neurocognitive function. Anesth Analg. 2008;106:1681-707.
MAILING ADDRESS:

Ana Carolina Leite Viana

Al. Álvaro Celso, 55 - Santa Efigênia

30150-260 - Belo Horizonte - MG

Brazil

E-mail:ac_leite_viana@yahoo.com.br

How to cite this article: Viana ACL, Gontijo B, Bittencourt FV. Giant congenital melanocytic nevus. An Bras Dermatol. 2013;88(6):863-78. 


\section{QUESTIONS}

\section{1 - Regarding the origin of congenital melanocytic nevi, it is cor- rect to affirm that:}

a) Its formation begins between the 24th and the 30th weeks of gestation

b) The presence of nevi in family members indicates its mainly genetic character

c) Proto-oncogenes c-met and c-kit play a role in its development

d) It is the translation of a morphologic error in mesoderm

2 - Regarding epidemiology, one can affirm that the giant nevus:

a) Affects 1 in 1,000 newborns

b) It is most common in males

c) The garment-like variant is the most rare one

d) It is most common in premature children

3 - Those are clinical characteristics of giant congenital melanocytic nevus, except:

a) Heterogeneous coloration

b) Irregular surface

c) Hypertrichosis

d) Ulceration

4 - Regarding the clinical aspects of giant congenital melanocytic nevus, one can affirm that:

a) Its most frequent location is on the head and / or neck

b) It may present depigmentation or even spontaneous regression

c) Pruritus occurs in the majority of cases

d) The appearance of nodules in the nevus, although common, deserves investigation

5 - A congenital melanocytic nevus is considered giant when it reaches the minimal diameter of how many centimeters during adulthood?
a) $10 \mathrm{~cm}$
b) $15 \mathrm{~cm}$
c) $20 \mathrm{~cm}$
d) $25 \mathrm{~cm}$

6 - Mark the incorrect affirmation regarding satellite lesions:

a) They occur in up to $80 \%$ of patients with giant nevi

b) They are associated, when in multiples, to a higher risk of melanoma

c) They indicate, when in larger numbers, a higher risk of neurologic involvement

d) They are most commonly associated with nevus on acral location

7 - A patient cannot receive the diagnosis of neurocutaneous melanosis when, besides having a giant congenital melanocytic nevus, he also presents:

a) Central nervous system's melanoma without evidence of cutaneous melanoma

b) Cutaneous melanoma and encephalic melanocytic lesion that is benign on histologic examination

c) Cutaneous melanoma and meningeal melanoma

d) Benign melanocytic proliferation in central nervous system without evidence of cutaneous neoplasm

8 - Regarding cutaneous and extra-cutaneous alterations associated to giant congenital melanocytic nevus, it is incorrect to state that:

a) Depigmentation in cases of vitiligo is interpreted as an autoimmune phenomenon, involving a response from the immunologic system to melanocytes' antigens.

b) The reduction in the circumference of the limb affected by the nevus is due to replacement of fatty tissue by nevus cells

c) Most alterations reported in the literature have a causal asso- ciation with the presence of nevic lesions.

d) Many cases of structural malformation in the central nervous system, such as arachnoid cysts, choroid plexus papilloma, cerebellar astrocytoma and spinal dysraphism, have been reported

9 - Regarding histologic findings in giant congenital melanocytic nevus, one can affirm that:

a) Their epidermic alterations allow them to be differentiated of acquired nevi

b) The presence of nevic cells is classically restricted to the papillary dermis

c) The occurrence of nevic cells inside sebaceous glands, nerve and blood vessels on the dermis is common

d) The histopathologic pattern usually presents homogenous morphology and architecture

10 - Regarding giant congenital melanocytic nevus dermoscopy, one can affirm all of the following, except:

a) Pigmentary network is most commonly present in lesions with irregular surface

b) The depth of nevic cells in the skin hinders the identification of structures in dermoscopy

c) Most lesions show a homogenous brownish coloration in the background with islands of darker pigmentation

d) Perifollicular hyperpgimentation, pseudomillia and vascular structures may be observed

11 - Regarding the diagnosis of neurocutaneous melanosis, mark the correct affirmative:

a) Computerized tomography scan is the most sensitive method to detect melanin

b) CSF analysis must be routinely performed to detect central nervous system involvement by nevic cells

c) Detection of free melanin in CSF is usual

d) The cases in which there is histological confirmation of lesions of the central nervous system are considered final

12 - Regarding the risk of developing melanoma in patients with giant congenital melanocytic nevus, it is incorrect to state that:

a) There is, in the literature, ample evidence that these individuals are at increased risk of developing the tumor

b) The rate of incidence of malignancy is well established, thanks to several prospective studies on the subject

c) It is estimated that for these individuals the lifetime risk of developing melanoma is between 5 and $10 \%$

d) The risk of developing tumor seems to be directly proportional to the size of the nevus

13 - Regarding melanoma that occurs associated with giant melanocytic nevus, is correct to say that:

a) It has better prognosis than de novo cutaneous melanomas

b) It appears usually after puberty

c) It has an unknown primary site in $25 \%$ of cases

d) It arises most commonly from the epidermis

14 - The following are also tumors that are associated with giant melanocytic nevus, except:

a) Neurofibroma

b) Schwannoma

c) Dermatofibroma

d) Rhabdomyosarcoma 
15 - About the nodules appearing on the giant congenital melanocytic nevus during the neonatal period, it can be said that:

a) From the histological point of view, they are easily distinguished from melanoma, by the positivity of HMB45

b) They suffer stabilization or regression after a period of rapid growth

c) They exhibit the same degree of atypia and high mitotic index observed in malignant melanocytic neoplasms

d) Most often, they present structural chromosomic changes

16 - Regarding neurocutaneous melanosis, select the incorrect statement:

a) The prevalence of asymptomatic neurocutaneous melanosis in patients with giant congenital nevus is greater than $40 \%$

b) Its symptoms appear most often in the first two years of life

c) Severe and chronic psychosis may be a clinical manifestation of this condition

d) Its most common signs and symptoms are headache, lethargy, vomiting, increased head circumference, seizures and papilledema

17 - There is evidence that the risk of neurocutaneous melanosis is associated with the following factors, except:

a) Location of giant congenital nevus on the head, neck and / or paravertebral region

b) Nevus with a roughness surface

c) Increased number of associated satellite lesions

d) The size of the congenital nevus

18 - About the treatment of giant congenital melanocytic nevus, one can affirm that:

a) The surgical removal of nevic lesion has proven efficient in preventing cutaneous melanoma

b) The diagnosis of symptomatic neurocutaneous melanosis affects the decision to surgically intervene or not, on the congenital nevus

c) Procedures such as dermabrasion, curettage and tangential excision have the same effectiveness in removing the nevus cells that of surgical excision

d) Currently there is a consensus that the interventionist approach on giant congenital melanocytic nevus is the best option for most patients

19 - Regarding the modalities of interventionist approach on giant congenital melanocytic nevus, select the false statement:

a) Although laser can improve the aesthetic appearance of lesions and reduce the number of melanocytic cells, it is feared that the cells exposed to sublethal doses of energy have greater likelihood of cancerization

b) Chemical peels can improve the appearance of lighter colored nevi

c) Surgical excision of the lesions usually depends on the use of tissue expanders, serial execution of operations, the use of skin grafts or flaps or a combination of more than one type of procedure

d) The dermabrasion and curettage are more effective if performed after 5 years of age

20 - Regarding the monitoring of patients with giant congenital nevus, one can affirm all the following, except that:

a) Palpation of both nevus lesion and lymph nodes, is an important act during the physical examination

b) Psychological support may be necessary, given that emotional or behavioral problems affect up to $26 \%$ of patients

c) Patients whose nevus has been completely removed by a dermatologist may be exempted from periodic examinations of the skin

d) Dermatoscopy may be unnecessary, particularly in the examination of lesions in which nevus cells are situated more deeply

\section{Answer key}

Paracoccidioidomycosis: epidemiological, clinical, diagnostic and treatment up-daing (5):700-11.

$\begin{array}{llll}\text { 1) } \mathrm{C} & \text { 6) } \mathrm{C} & \text { 11) } \mathrm{D} & \text { 16) } \mathrm{D} \\ \text { 2) } \mathrm{D} & \text { 7) } \mathrm{A} & \text { 12) } \mathrm{D} & \text { 17) } \mathrm{D} \\ \text { 3) } \mathrm{B} & \text { 8) } \mathrm{A} & \text { 13) } \mathrm{D} & \text { 18) } \mathrm{D} \\ \text { 4) } \mathrm{B} & \text { 9) } \mathrm{D} & \text { 14) } \mathrm{A} & \text { 19) } \mathrm{D} \\ \text { 5) } \mathrm{C} & \text { 10) } \mathrm{D} & \text { 15) } \mathrm{D} & \text { 20) } \mathrm{D}\end{array}$

\section{Papers}

Information for all members: The EMC-D questionnaire is now available at the homepage of the Brazilian Annals of Dermatology: www.anaisdedermatologia.org.br. The deadline for completing the questionnaire is 30 days from the date of online publication. 